\title{
Review of the genus Paronychiurus (Collembola: Onychiuridae) and description of two new species
}

\author{
ROMUALD J. POMORSKI \\ Zoological Institute, Wrocław University, Sienkiewicza 21, P1-50-335 Wrocław, Poland; e-mail: onychus@biol.uni.wroc.pl
}

Key words. Collembola, Onychiuridae, Paronychiurus, North America, new species, diagnosis, key

\begin{abstract}
A new diagnosis of Paronychiurus Bagnall, 1948 is given. P. ramosus (Folsom, 1917) and P. eous (Christiansen \& Bellinger, 1980) comb. nov. are redescribed on the basis of the types and new specimens. Two new species are described: $P$. probus sp. n., $P$. hubbardi sp. n. A key to the species in this genus is presented.
\end{abstract}

\section{INTRODUCTION}

The genus Paronychiurus was established by Bagnall (1948) for Onychiurus ramosus Folsom, 1917. This taxon was recognised as a genus or subgenus by Stach (1954), Salmon (1964), Palissa (1964), Babenko et al. (1988), Weiner (1996) and Pomorski (2000), only Gisin (1960) and Christiansen \& Bellinger $(1980,1989)$ regarded it as synonymous with Onychiurus Gervais, 1841. Bagnall listed the following features in his diagnosis of Paronychiurus: "PAO with compound vesicles, anterodorsal pseudocellus of the head situated outside the demarcated basal area of the antenna, head postero-marginal pseudocelli absent, lateral thoracic (or proximal praecoxal) pseudocelli also absent". It is surprising that for many years these distinguishing characters were overlooked. The most important character generally used to distinguish the genus was the complicated vesicles in the PAO. Weiner (1996) in her revision was the first person to use all the characteristics in Bagnall's definition. Largely as a result of Salmon's (1964) misinterpretation of the genus, various species with compound vesicles, belonging to other genera were placed in Paronychiurus, producing some nomenclatorial confusion within the Onychiurinae. For example, Salmon (1964) placed 40 species within this genus and the authors of the Check-list of the Collembola (http://www.geocities.com/ fransjanssens/taxa/onycinae. htm), updated in January 2001, placed 57 species.

Thanks to the kindness of Prof. Kenneth Christiansen I received several specimens of $P$. ramosus and unidentified specimens, classified as "near ramosus" and "near eous". Detailed studies of $P$. ramosus confirmed the accuracy of Bagnall's generic decision and showed that a clear majority of Onychiurinae species, classified as Paronychiurus, do not belong in this genus.

Among the unidentified specimens were 2 new species of Parnychiurus. I also examined the type specimens of the North American Onychiurus eous Christiansen \& Bellinger, 1980, received from the Museum of Comparative Zoology at Harvard University. The investigation of the material mentioned above convinced me the diagnosis of this genus needed revision.

\section{Paronychiurus Bagnall, 1948}

Ramonychiurus Stach, 1954. Państ. Wyd. Nauk., Kraków: 25.

Type species. Onychiurus ramosus Folsom, 1917, by original designation (described from North America: Canada, USA).

Diagnosis. Body without lateral pseudocelli. Posterior dorsal cephalic pseudocelli absent. Thoracic tergum I and abdominal tergum III without pseudocelli. Cuticular granulation strong with granular areas. Furca reduced to small depression with 2 small, posterior setae, in contact with the border between abdominal sterna III and IV. Anal spines located on distinct papillae. Distal whorl of setae on tibiotarsi symmetrical, with 11 setae. Antennal III sense organ with 4 simple papillae and 4-5 guard setae. Vesicles in PAO compound. Labium with all five papillae, AC type (according to terminology of Fjellberg, 1999). Chaetotaxy on terga consists of two kinds of setae: Blunt rod-like mesosetae and pointed microsetae, "sensory" setae on head and body poorly differentiated, abdominal tergum VI with 2 medial setae.

Discussion. The genus Paronychiurus is a monophyletic group of the Hymenaphorurini with 3 diagnostic apomorphies: compound vesicles in PAO, furca as described above, and differentiation of the setae into blunt rod-like mesosetae and pointed microsetae. The genus shares with Heteraphorura Bagnall, 1948 and Psyllaphorura Bagnall, 1948 the synaphomorphy of lacking pseudocelli on abdominal terga II-III. In addition, Paronychiurus like Psyllaphorura has the anterodorsal pseudocellus of the head situated outside the demarcated basal area of the antenna (except in P. eous). The complexity of vesicles in PAO is shared with Heteraphorura.

\section{SPECIES DESCRIPTIONS}

\section{Paronychiurus ramosus (Folsom, 1917) (Figs 1-10)}

Redescription. Colour white. Size without antennae: Males $1.0-1.2 \mathrm{~mm}$, females $1.3 \mathrm{~mm}$. Shape of body squat and broad (Figs 1-2). Antennae as long as head or a little shorter. Furca reduced to small depression, in contact with the border between abdominal sterna III and IV, with 2 small posterior setae (Fig. 6). Cuticular granulation 


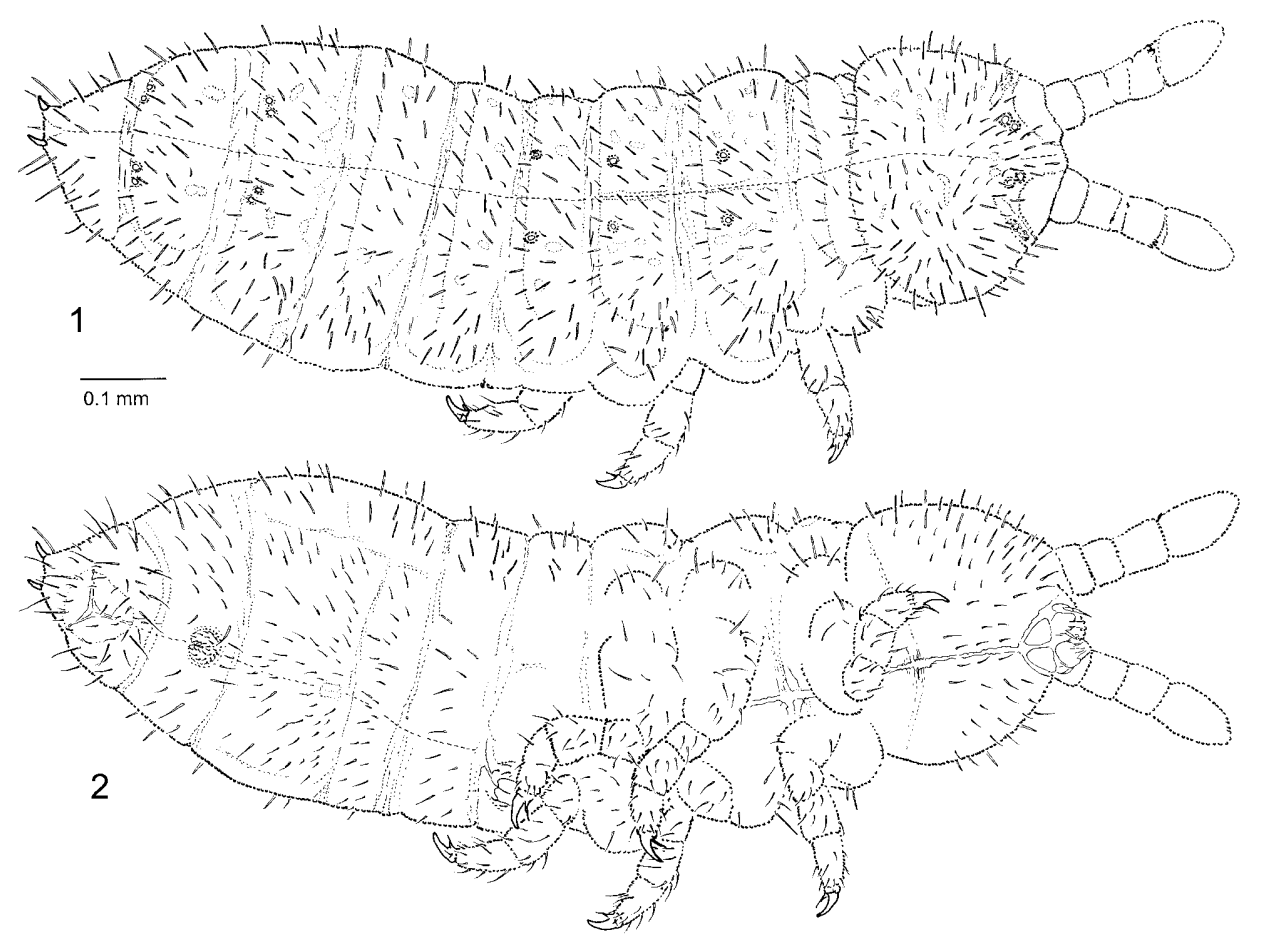

Figs 1-2. Paronychiurus ramosus. 1 - habitus and dorsal chaetotaxy; 2 - habitus and ventral chaetotaxy.

on dorsal surface of the body regular, with indistinct areas of coarser granules. Usually $12-15$ granulae around each pseudocellus.
Antennal III sense organ with 4 guard setae, 4 low conical papillae, 2 sensory rods and 2 granulated sensory clubs (Fig. 3-4).
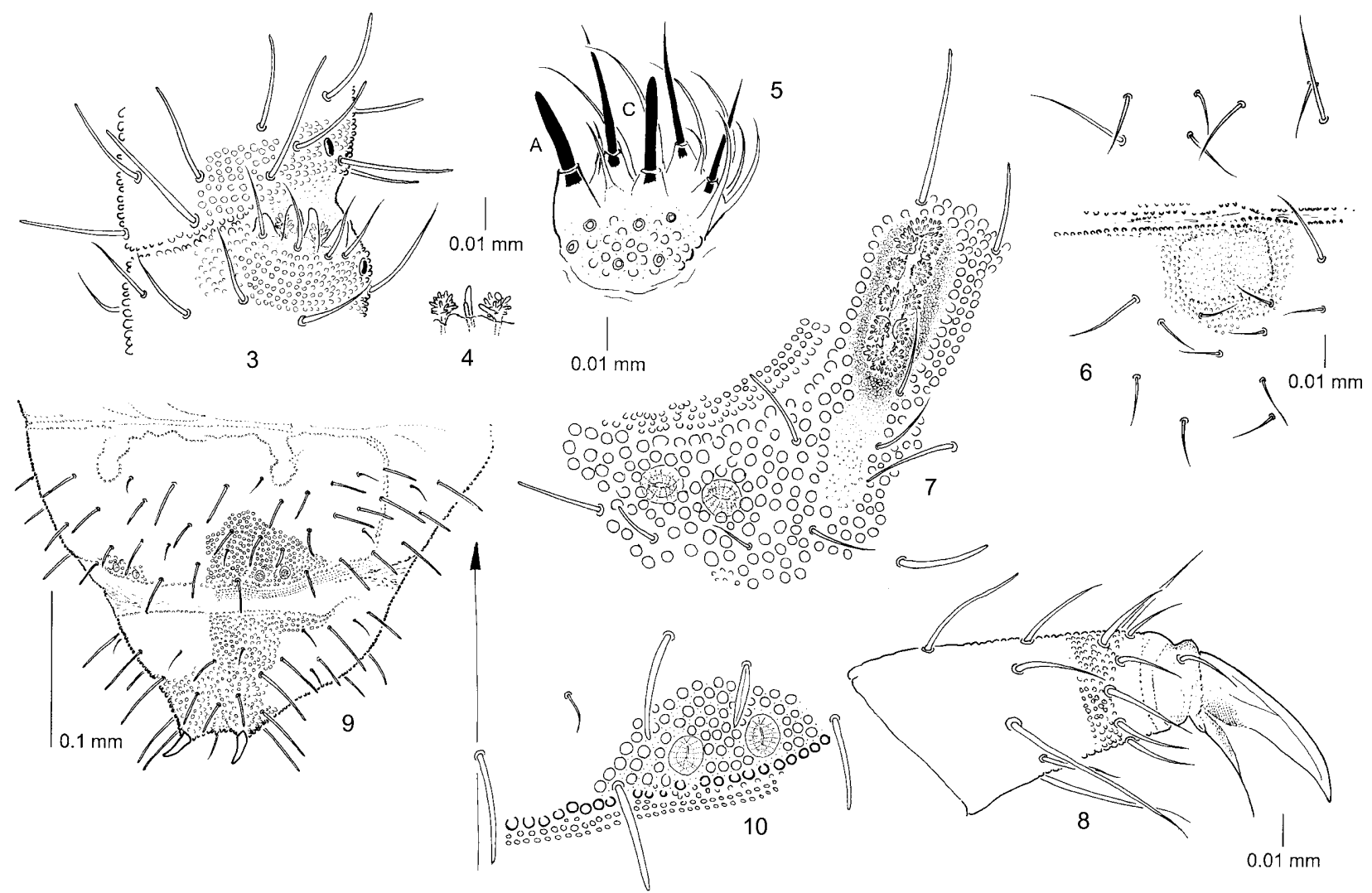

Figs 3-10. Paronychiurus ramosus. 3 - antennal III sense organ; 4 - antennal III sense organ - sensory clubs; 5 - labium, A and C thickened labial papillae; 6 - remnant of furca; 7 - postantennal organ and anterior cephalic pseudocelli; 8 - tibiotarsal chaetotaxy and claw; 9 - abdominal segments V-VI; 10 - pseudocelli and setae on abdominal tergum V. 


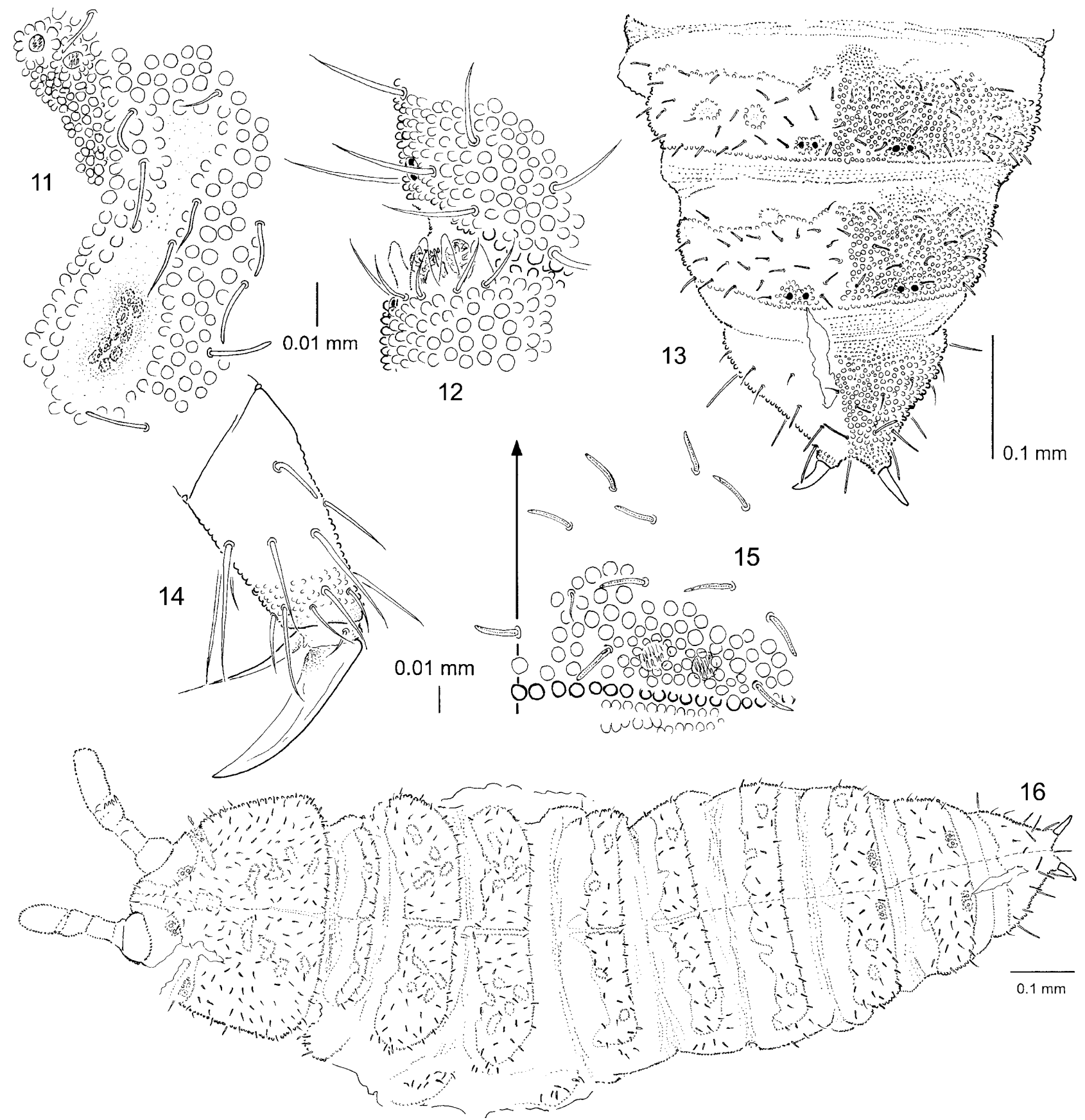

Figs 11-16. Paronychiurus eous. 11 - postantennal organ and anterior cephalic pseudocelli; 12 - antennal III sense organ; 13 chaetotaxy of abdominal terga IV-VI; 14 - tibiotarsal chaetotaxy and claw; 15 - pseudocelli and setae on abdominal tergum V; 16 habitus and dorsal chaetotaxy (paratype).

Antennal segment IV with subapical organ and ms located in the same row of the posterior setae. Microsensillum of antennal segment III lateral and slightly posterior to the antennal III sense organ (Fig. 3).

$\mathrm{PAO}$ in a long cuticular groove with 2 acuminate border setae, consisting of $11-13$ very fine granulated vesicles (Fig. 7).

Pseudocellar formula 20/011/10022, anterior cephalic pseudocelli located outside the delimited antennal basal area. Subcoxae and venter of body without pseudocelli. Parapseudocelli invisible.

Labium AC type (Fig. 5).
Dorsal chaetotaxy with well differentiated blunt rodlike mesosetae and pointed microsetae, as in Figs 1, 9. Head with seta $\mathrm{d}_{0}$. Abdominal tergum IV with medial $\mathrm{m}_{0}$ and $\mathrm{p}_{0}$ setae, abdominal tergum $\mathrm{V}$ with $\mathrm{p}_{0}$ seta, abdominal tergum VI with 2 medial setae. Thorax II-III with lateral microsensilla. Subcoxae with $5-6,5,5$ setae. No setae between legs on pro-, meso- and metasternum. Ventral tube with $8+8$ setae, without setae at base. $1+1$ "sensory" setae visible only on abdominal tergum V (Fig. 10).

Male ventral organ absent.

Claw without inner tooth, empodial appendage nearly as long as inner edge of the claw, without basal lamella 

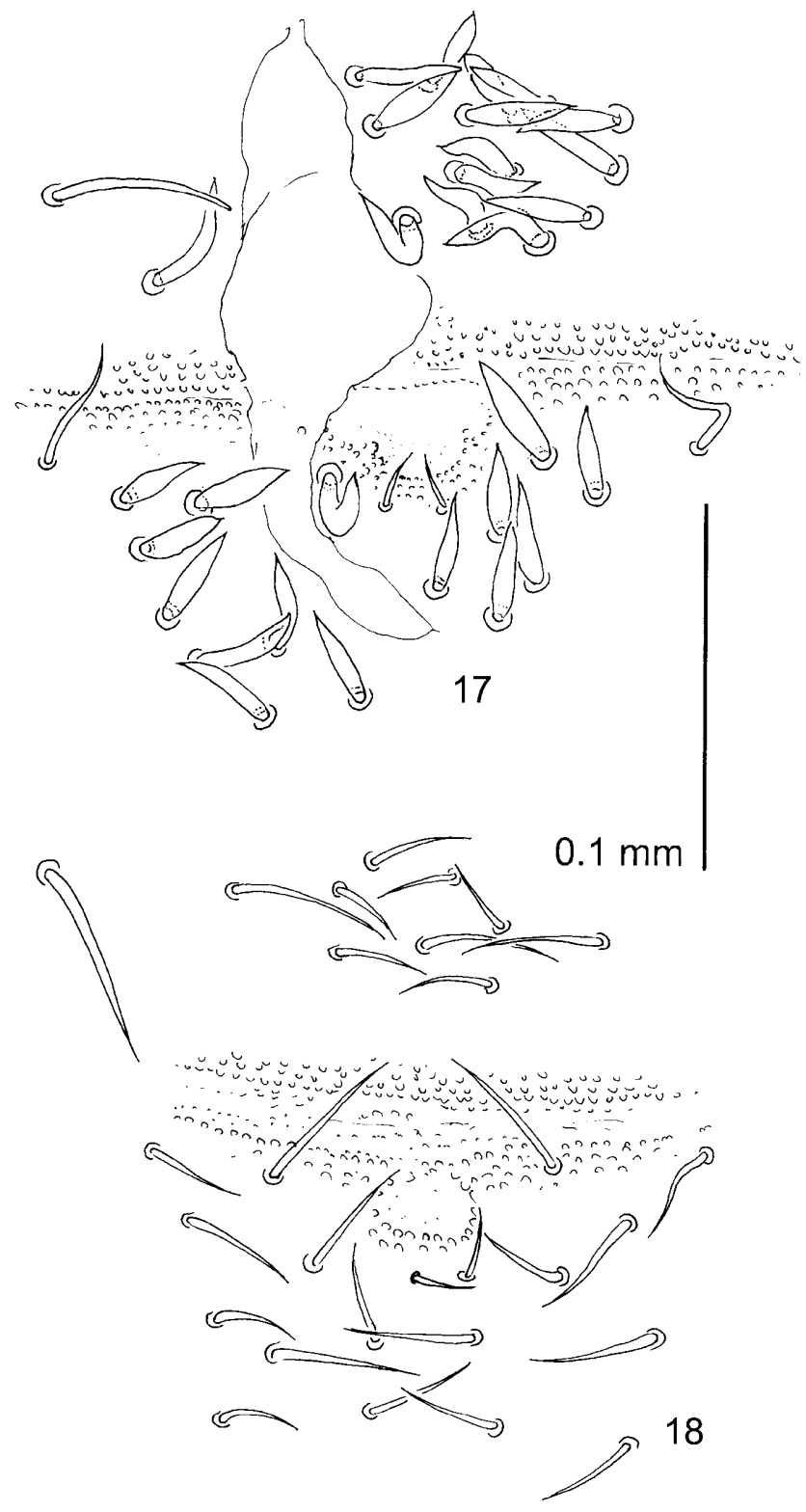

Figs 17-18. Paronychiurus eous. 17 - remnant of furca and male ventral organ (holotype - reproductive male); 18 - remnant of furca of female.

(Fig. 8). Distal whorl of setae on tibiotarsi symmetrical, with 11 setae.

Anal spines on distinct basal papillae, slender, weakly curved and about 0.5 length of hind claw.

Material examined. 3 unreproductive males, 5 females, 1juv. (2897, 2898); USA, Wyoming, Albany Co., 8 miles N. W. Centennial, elev. 10,000', Medicine Bow National Forest Cutthroat lake; 5 VIII 1971, coniferous forest, under bark and on rotten wood, leg. K. Christiansen. Immature male (7970); USA, Indiana, Harrison Co., Coon cave $\sim 5$ mi. S.W. Corydon; 9 VI 1996, leaf litter, leg. Jerry Lewis; Female (9291), USA, Indiana, Harrison Co., cave Devil's staircase; 9 XI 1997, leg. Jerry Lewis.

Paronychiurus eous (Christiansen \& Bellinger, 1980) comb. n. (Figs 11-18)

Onychiurus eous Cristiansen \& Bellinger, 1980
Redescription. Colour white. Length without antennae: Unreproductive male (holotype) $2.2 \mathrm{~mm}$, females 2.2-2.6 $\mathrm{mm}$. Shape of body fusiform (Fig. 16). Antennae distinctly shorter than head. Furca reduced to a small depression, in contact with border between abdominal sterna III and IV, with 2 small posterior setae, thickly surrounded by a group of 18-20 setae on abdominal sternum IV and 10 similar setae on abdominal tergum III (Fig. 18). In males the setae are thicker and form a male ventral organ (Fig. 17). Cuticular granulation on dorsal surface of the body strong, regular, with distinct coarsely granulated areas, finer granulation around abdominal pseudocelli and coarser granulation around cephalic pseudocelli. Usually 8-11 grains around each pseudocellus.

Antennal III sense organ with 4 low conical papillae and 5 guard setae, 2 sensory rods and 2 spherical, finely granulated sensory clubs (Fig. 12).

Antennal segment IV with subapical organ and ms located in the row of posterior setae. On antennal segment III microsensillum lateral and slightly posterior to the antennal III sense organ (Fig. 12).

$\mathrm{PAO}$ in a long cuticular groove with 2 pointed border setae, consists of 8-12 very fine granulated vesicles (Fig. 12).

Pseudocellar formula 20/00(1)0/00022, anterior cephalic pseudocelli located within the delimited antennal basal area. Subcoxae and ventral part of body without pseudocelli. Parapseudocelli invisible.

Labium AC type.

Dorsal chaetotaxy with a tendency to asymmetry on abdominal terga IV and V. Setae well differentiated into blunted rod-like mesosetae and pointed microsetae, as in Fig. 15. "Sensory" setae invisible. Head without seta $\mathrm{d}_{0}$. Submedial setae on abdominal tergum V always asymmetrial. Abdominal tergum VI with 2 medial setae. Thorax II-III with lateral microsensilla. Subcoxae with 7-8, 7-8, 5-6 setae. No setae between legs on pro-, meso- and metasternum. Ventral tube with $6+6$ setae, without basal setae.

Male ventral organ consists of 10-12 thickened setae situated on the posterior edge of abdominal sternum III and 16-18 similar setae on the anterior edge of abdominal sternum IV around the furca remnant (Fig. 17).

Claw without tooth, empodial appendage nearly as long as inner edge of the claw, without basal lamella (Fig. 14). Distal whorl of setae on tibiotarsi symmetrical, with 11 setae.

Anal spines on distinct basal papillae, moderately thick, weakly curved, $0.8-0.9$ the length of hind claw.

Type material. Holotype unrepoductive male, paratypes 3 females; USA, Iowa, Clayton Co., White Pine Hollow State Park; 17 V 1959; "Tullgren extract of bat guano in shallow cave"; leg. K. Christiansen. (slide No. 32688, kept in the Museum of Comparative Zoology Harvard University).

Remarks. The type specimens are strongly crumpled and for this reason the drawings do not show the true shape of this species. 

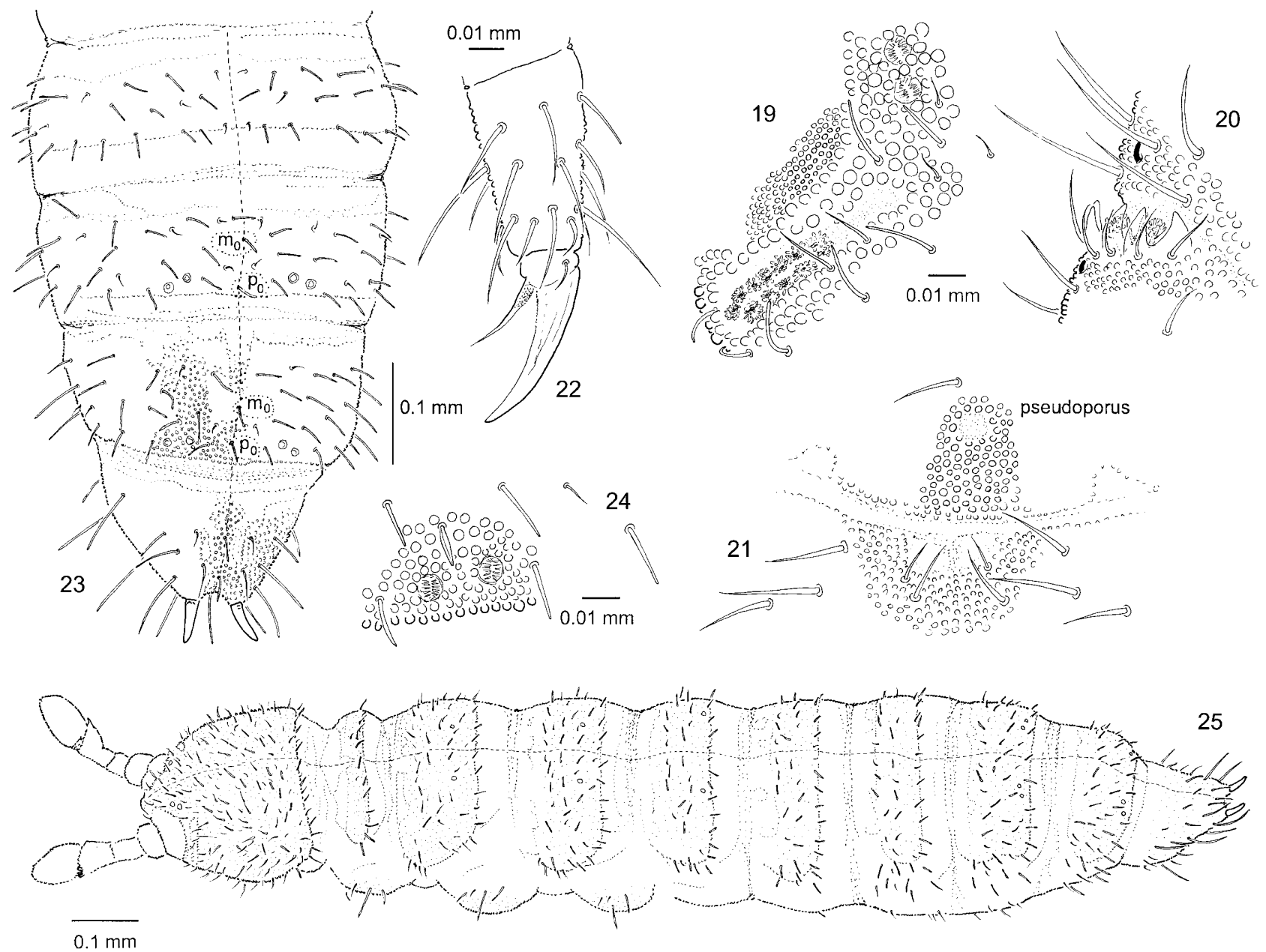

Figs 19-25. Paronychiurus probus sp. n. 19 - postantennal organ and anterior cephalic pseudocelli; 20 - antennal III sense organ; 21 - remnant of furca; 22 - tibiotarsal chaetotaxy and claw; 23 - chaetotaxy of abdominal terga III-VI; 24 - pseudocelli and setae on abdominal tergum V; 25 - habitus and dorsal chaetotaxy (holotype).

\section{Paronychiurus probus sp. n. (Figs 19-25)}

Diagnosis. This species is close to P. ramosus, from which it differs in the presence of 5 guard setae in antennal III sense organ ( $P$. ramosus: 4 guard setae). In addition the two species have distinctly different body shapes (Fig. 2 vs. Fig. 25).

Description. Colour white. Length without antennae: Males $1.3 \mathrm{~mm}$, females $1.6-1.8 \mathrm{~mm}$ (holotype $1.8 \mathrm{~mm}$ ) Shape of body fusiform (Fig. 25). Antennae as long as head or a little shorter. Furca reduced to a small depression in contact with the border between the abdominal sterna III and IV, with 2 small posterior setae (Fig. 21). Cuticular granulation on dorsal surface of the body regular with distinct granular areas. Usually 11-12 grains around each pseudocellus.

Antennal III sense organ consists of 4 low conical papillae; 2 rod-like sensory rods; 2 granulated sensory clubs; 5 guard setae (Fig. 20).

Antennal segment IV with subapical organ and ms located in the row of posterior setae. Microsensillum of antennal segment III lateral and slightly posteror to the antennal III sense organ. (Fig. 20).
PAO in a long cuticular groove with 2 pointed border setae, consists of 12-13 very finely granulated vesicles (Fig. 19).

Pseudocellar formula 20/011/10022, anterior cephalic pseudocelli located outside of the delimited basal antennal area. Subcoaxae, ventral part of body without pseudocelli. Parapseudocelli invisible.

Labium AC type.

Dorsal chaetotaxy well differentiated into blunt rodlike mesosetae and pointed microsetae, as in Figs 23, 24. Head without seta $d_{0}$. Abdominal terga IV-V with medial $\mathrm{m}_{0}$ and $\mathrm{p}_{0}$ setae, abdominal tergum VI with 2 medial setae. Thorax II-III with lateral microsensilla. Subcoxae with $4,4,3$ setae. No setae between legs on pro-, mesoand metasternum. Ventral tube with $8+8$ setae, without setae at base. 1+1 "sensory" setae visible only on abdominal tergum $\mathrm{V}$ (Fig. 24).

Male ventral organ absent.

Claw without inner tooth, empodial appendage without basal lamella, 0.5-0.7 the length of inner edge of the claw (Fig. 22). Distal whorl of setae on tibiotarsi symmetrical, with 11 setae. 

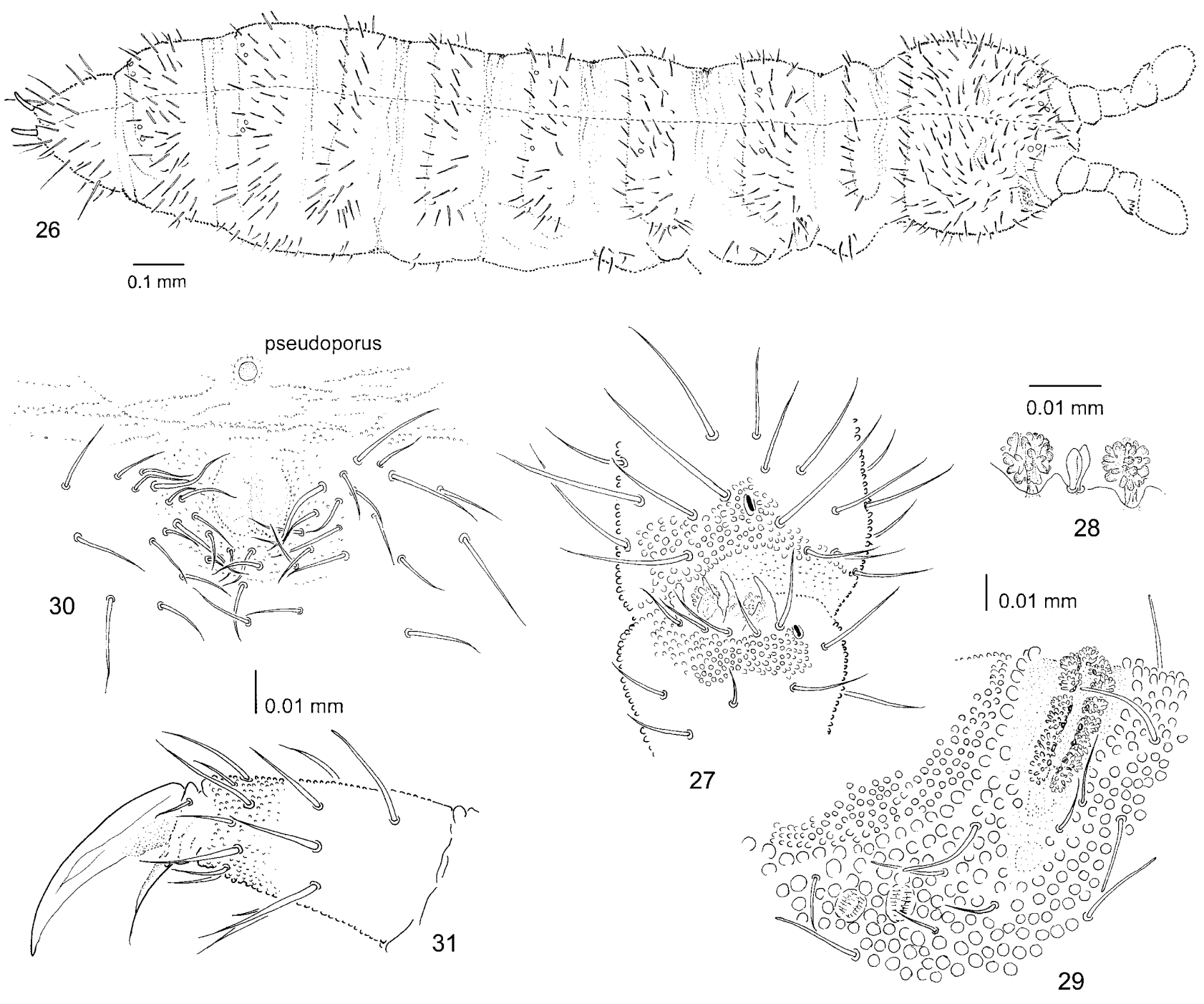

Figs 26-31. Paronychiurus hubbardi sp. n. 26 - habitus and dorsal chaetotaxy (holotype); 27 - antennal III sense organ; 28 antennal III sense organ - sensory clubs; 29 - postantennal organ and anterior cephalic pseudocelli; 30 - remnant of furca; 31 - tibiotarsal chaetotaxy and claw.

Anal spines on distinct basal papillae, thick, apically blunt, weakly curved and as long as hind claw.

Type material. holotype female, 3 paratypes ( 2 female, 1juv.) (9485); USA, Virginia, Russell Co., Bush Handline cave; 11 I 2000, water surface, leg. D. Hubbard (in the Illinois Natural History Survey collection).

Other material. 2 females (9349); USA, Virginia, Russell Co., Mountain View cave; 22 IV 1998, on water surface, leg. D. Hubbard. Unreproductive male, 2 females (9514): USA, Virginia, Smyth Co., DATA Little Saltpetre cave, leg. D. Hubbard. 2 females (7911); USA, Virginia, Montgomery Co., Adams cave; 22 XI 1995, on bat guano, leg. D. Hubbard. Juv. (9480); USA, Virginia, Scott Co., Valley Creek Pirate cave; 14 XII 1999, leg. D. Hubbard. Male (7941); USA, Virginia, Scott Co., Lawson's Saltpetre cave; 10 IV 1996, leg. D. Hubbard.

Etymology. The name of the new species is derived from the Latin "probus" - upright, honourable. I dedicate the new species to Mrs Danuta Przywara and all members of the "Informal Society of Lovers of Springtails" at the Helsinki Foundation for Human Rights in Warsaw.

\section{Paronychiurus hubbardi sp. n. (Figs 26-31)}

Diagnosis. This species is closely related to $P$. probus, from which it differs by more numerous groups of setae around the furca remnant.

Description. Colour white. Length without antennae: Males 1.2-1.6 mm, females 1.4-1.6 mm (holotype 1.25 $\mathrm{mm}$ ). Shape of body fusiform (Fig. 26). Antennae as long as head or a little shorter. Furca reduced to a small depression, in contact with the border between abdominal sterna III and IV, with 2 small posterior setae, enclosed by a group of 28-30 setae on abdominal sternum IV. This group of setae occurs in both sexes (Fig. 30). Cuticular granulation on the dorsal surface of the body regular with distinct granular areas. Usually 11-12 cuticular grains around each pseudocellus.

Antennal III sense organ consists of 4 low conical papillae; 2 slightly swollen sensory rods; 2 granulated sensory clubs and 5 guard setae (Fig. 27).

Antennal segment IV with subapical organ and ms located in the row of posterior setae. Microsensillum of 
antennal segment III lateral of and slightly posterior to the antennal III sense organ. (Fig. 27).

$\mathrm{PAO}$ in a long cuticular groove with 2 pointed border setae, consists of 14-16 very finely granulated vesicles (Fig. 29).

Pseudocellar formula 20/011/10022, anterior cephalic pseudocelli located outside the delimited antennal basal area. Subcoxae, ventral part of body without pseudocelli. Parapseudocelli invisible.

Labium AC type.

Dorsal chaetotaxy well differentiated into blunt rodlike mesosetae and pointed microsetae, as in Fig. 26. Head without seta $\mathrm{d}_{0}$. Abdominal tergum IV with medial $\mathrm{m}_{0}$ and $\mathrm{p}_{0}$ setae, abdominal tergum $\mathrm{V}$ with $\mathrm{p}_{0}$ seta, abdominal tergum VI with 2 medial setae. Thorax II-III with lateral microsensilla. Subcoxae with 4(5), 4, 3 setae. No setae between legs on pro-, meso- and metasternum. Ventral tube with $8+8$ setae, lacks setae at base. $1+1$ "sensory" setae visible only on abdominal tergum $\mathrm{V}$.

Male ventral organ absent.

Claw without teeth, empodial appendage without basal lamella $0.5-0.7$ the length of inner edge of the claw (Fig. 31). Distal whorl of setae on tibiotarsi symmetrical, with 11 setae.

Anal spines on distinct basal papillae, strong, blunt, weakly curved, as long as hind claw.

Type material. Holotype reproductive male (7935); USA, Virginia, Wise Co., Powell Mountain, Saltpetre cave; 27 II 1996, in litter, Leg, D. Hubbard. 4 paratypes (females) (7936) USA, Virginia, Wise Co., Ridge cave 8 III 1996, leg. D. Hubbard (kept in the Illinois Natural History Survey).

Other material. 2 females (7910) USA, Virginia, Wise Co., Buchanan cave No. 2; 30 X 1995, leg. D. Hubbard; 3 unreproductive males, 6 females (7912); USA, Virginia, Wise Co., Huff's cave; 22 XI 1995, leg. D. Hubbard.

Etymology. I dedicate the new species to David Hubbard, who collected the new species material and has "produced" more new species of Collembola from U.S. caves than anybody else for many years.

\section{KEY TO SPECIES OF PARONYCHIURUS (FOR ADULTS AND SUBADULTS ONLY)}

1. Anterior cephalic pseudocelli located outside the delimited antennal basal area. (Figs 1, 8), pseudocellar formula 20/011/10022 2 .
- Anterior cephalic pseudocelli located inside the delimited antennal basal area. (Figs 11, 16) pseudocellar formula $20 / 000(1) / 000$ P. eous (Christiansen \& Bellinger, 1980)

2. Antennal III sense organ with 4 papillae and 4 guard setae; body squat and broad (Figs 1-2) ..................... P. ramosus (Folsom, 1917)

- Antennal III sense organ with 4 papillae and 5 guard setae;

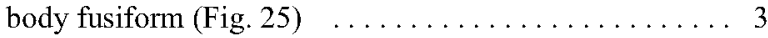

3. Furca without an additional group of setae on abdominal sternum IV. (Fig. 21) . . . . . . . . . P. probus sp. n.

- Furca enclosed by a group of 28-30 setae located on abdominal sternum IV. (Fig. 30) … P. hubbardi sp. n.

ACKNOWLEDGEMENTS. I wish to express my sincere thanks to Prof. Kenneth Christiansen for his critical remarks, helpful comments on the manuscript and loan of material.

\section{REFERENCES}

Babenko A.B., Kuznetsova N.A., Potapov M.B., Stebaeva S.K., Khanislamova G.M. \& Chernova N.M. 1988: Key to Identification of the Collembola Fauna of the Soviet Union. Nauka, Moscov, 214 pp. [in Russian]

BAGNALL R.S. 1948: Contributions towards a knowledge of the Onychiuridae (Collembola-Onychiuroidea), I-IV. Ann. Mag. Nat. Hist. 11: 631-642.

Christiansen K. \& Bellinger P. 1980: The Collembola of North America North of the Rio Grande. First edition. Grinnell College, Grinnel, $1321 \mathrm{pp}$.

ChristiAnsen K. \& Bellinger P. 1989: The Collembola of North America North of the Rio Grande. Second edition. Grinnell College, Grinnel, $1518 \mathrm{pp}$.

FJellberg A. 1999: The labial palp in Collembola. Zool. Anz. 237: 309-330.

Grsin H. 1960: Collembolenfauna Europas. Muséum d'histoire naturelle, Genève, $312 \mathrm{pp}$.

Palissa A. 1964: Die Tierwelt Mitteleuropas. Band IV, I Teil, Apterygota. Quelle and Meyer, Leipzig, $405 \mathrm{pp}$.

Pomorski R.J. 2000: Arneria - a new genus of North American Onychiuridae (Collembola), with a description of two new species. Insect Syst. Evol. 31: 317-322.

Salmon J.T. 1964: An Index to the Collembola. Vol. 1-2, Society Victoria University of Wellington, Wellington, 144 pp.

STACH J. 1954: The Apterygotan Fauna of Poland in Relation to the World-Fauna of this Group of Insects. Onychiuridae. PAN, Kraków PWN, 219 pp.

WEINER W.M. 1996: Generic revision of Onychiuridae (Collembola: Onychiuridae) with cladistic analysis. Ann. Soc. Entomol. Fr. (N.S.). 32: 163-200.

Received April 23, 2002; revised October 4, 2002; accepted November 6, 2002 